\title{
El narcotráfico en área de penal \\ Reflexiones sobre goles y carteles de la droga en Colombia
}

David Leonardo Quitián Roldán ${ }^{1}$

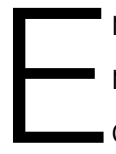

n agosto de 2007 los cables noticiosos del mundo daban cuenta de un hecho corrien-

te en Colombia: la aprehensión, en Brasil, de un presunto capo de la droga de nacionalidad colombiana. Sin embargo, pese a la normalidad que para los colombianos entraña desde principios de la década del ochenta ese tipo de información, si hubo estupefacción generalizada por la identidad del hombre atrapado por la policía secreta de Sao Paulo y por el rótulo de "capo" que se le daba; se trataba, ni más ni menos, que del autor del gol más recordado en la historia del fútbol nacional: Freddy Rincón, acusado de blanqueo de dinero y solicitado en extradición por la justicia de Panamá. La "Espiga" Rincón, con su reseña policial, pasaba de ser el héroe deportivo de la Copa Mundo Italia 90 (cuando marcó "in extremis" el gol del empate ante los alemanes) a ser un narcotraficante más de la escrupulosa lista del Departamento Estadounidense Antidrogas DEA.

Claro que esa noticia, examinada con cuidado, no debería despertar tanta sorpresa en la opinión pública colombiana, ya que tres meses antes hubo una de un talante similar: Luis Eduardo Méndez, ex presidente del primer club colombiano que ganó el título nacional, el Independiente Santa Fe, se entregó a la justicia del estado de la Florida que desestimó

\footnotetext{
1 Profesor de las universidades Pedagógica Nacional,
} Incca de Colombia y de los Llanos. 
los cargos en los que se le imputaba la exportación de cocaína al país del norte, pero que finalmente lo condenó a pagar 70 meses de prisión por obstruir a la justicia de Estados Unidos al facilitar el escape del narcotraficante Rafael Caicedo, hoy tras las rejas en una penitenciaría norteamericana. Así mismo el corresponsal de la Agencia EFE en Bogotá informó a sus abonados, en marzo de este año, que José Ignacio Martán, miembro del Comité Ejecutivo de la Federación Colombiana de Fútbol, había sido vinculado a un proceso judicial en el que se le sindicaba de asociarse con el Cartel del Norte del Valle ${ }^{2}$ en el tráfico de drogas y por ello su nombre y la razón social del equipo que presidía, el Cortuluá Fútbol Club que participa en la categoría de ascenso (la Primera B), pasó a integrar la famosa "Lista Clinton" que es el temido listado financiero que la Oficina de Control Activos Extranjeros (OFAC) confecciona con los nombres de las personas y empresas sindicadas de lavado de activos provenientes de la mafia narcotraficante.

Siguiendo con la relación reciente de hechos en los que el tráfico de drogas y el fútbol colombiano aparecen en el mismo titular noticioso, mencionemos el frustrado escándalo originado, el 21 de junio de 2007, por el sensacionalista Diario The Sun de Inglaterra en el que el talentoso ex delantero de los clubes Newcastle United FC y Parma FC, Faustino Asprilla, es señalado como "barón de la droga" al relacionarlo como socio del reconocido traficante Osmiro Méndez que es buscado por autoridades inglesas e italianas por el envío de varias toneladas de cocaína al Reino Unido y a la bota itálica. Vale decir que al día siguiente de publicada dicha noticia, el diario británico se retractó de la misma y ofreció excusas al polémico ex jugador que es célebre en Colombia por sus goles con la tricolor (en especial por los dos tantos marcados a la selección argentina en el humillante 5 a 0 que los "cafeteros" le infligieron a los "gauchos" en la eliminatoria mundialista de 1993), por su afición a las mujeres, a los caballos y a las pistolas ${ }^{3}$.

Para ir rematando este breve prontuario de gente de fútbol asociada a carteles del narcotráfico, refiramos la publicación de un informe confidencial de la Revista Semana (08/11/2007) que revela los negocios fraudulentos de paramilitares con equipos de fútbol del rentado nacional. Los negociados incluían infiltración de fichas ${ }^{4}$ en la División Mayor del Fútbol Colombiano (Dimayor) y la Federación Colombiana de Fútbol (Fedefútbol); sobornos de árbitros, arreglo de partidos, transacciones de pases de jugadores e, incluso, la compra de

\footnotetext{
2 Organización narcotraficante derivada del antiguo Cartel de Cali conducido por la familia Rodríguez Orejuela.

3 Hace un tiempo el 'Tino' Asprilla está en boca de toda Colombia por ser el primer hombre en la historia patria que aparece desnudo en la portada de una revista de farándula de circulación nacional. Cf. / Soho/ No. 89, septiembre 2007 .

4 El sociólogo Álvaro Camacho Guizado nos explica en el libro Droga y sociedad en Colombia: El poder y el estigma (Bogotá: CEREC-CIDSE, 1988) que la expresión "infiltración de fichas" es propia del argot narcotraficante y denota la inclusión de un miembro de la banda en una estructura ajena que se quiere vigilar o controlar.
} 


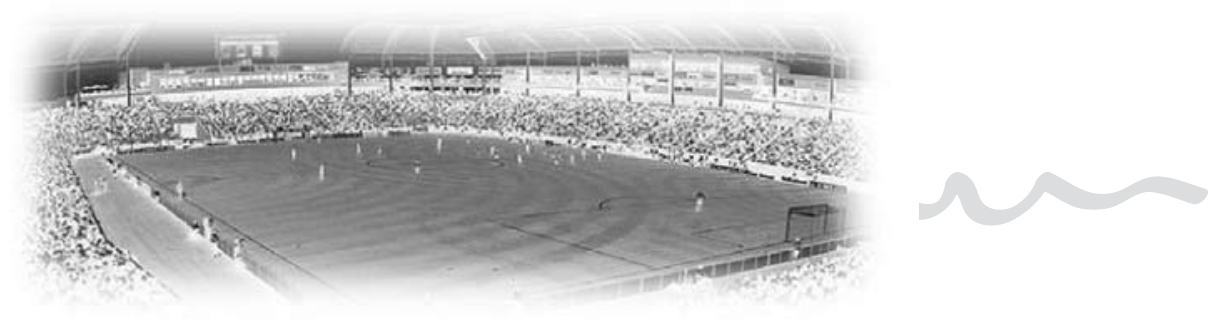

una empresa que serviría como fachada de testaferros: el Deportivo Independiente Medellín, prestigioso equipo de fútbol antioqueño en el que figuran respetables accionistas como los directores técnicos Francisco Maturana y Hernán Darío Gómez considerados héroes nacionales por sus éxitos premundialistas con la selección mayor ${ }^{5}$. La investigación de Semana señala que los dineros para financiar esas actividades comerciales non santas provenían de la extorsión y el narcotráfico. Total: toda una red de fraudes e ilícitos orquestados por el hampa paramilitar que produjo una encendida controversia nacional y una avalancha de declaraciones públicas (incluidas las de los técnicos aludidos), comunicados de prensa y desmentidos oficiales en un juego de "dimes y diretes" que ocuparon buena parte de los editoriales de prensa y fueron el tema del día en los programas deportivos y de opinión del periodismo colombiano.

Para colmo de males, en el ya de por si agitado medio colombiano, el hijo mayor del clan Rodríguez Orejuela lanzó al mercado editorial, a mediados del mes de septiembre de 2007, un libro titulado El hijo del ajedrecista (Bogotá: Oveja Negra y Quintero Editores, 2007) en clara alusión al alias con que su progenitor era conocido en los círculos policivos y en la sociedad en general. En tan explosivo texto, el autor en su calidad de informante privilegiado relata como su padre y su tío construyeron un imperio económico que filtró buena parte de la sociedad vallecaucana y nacional a través de emporios periodísticos, empresariales, deportivos y bursátiles alimentados con dineros provenientes del tráfico de sustancias ilícitas. Así, en un capítulo lleno de datos sorprendentes, Fernando Rodríguez Mondragón cuenta cómo el Cartel de Cali y sus socios de otras regiones introdujeron "dineros calientes" en la entraña del deporte rey en Colombia: el fútbol. Entonces, gracias a esa nefasta bonanza de dólares, llegaron al país algunos de los mejores jugadores suramericanos del momento como Óscar 'Pinino' Mas, Aurelio José Pascuttini, Roberto Cabañas, Julio César Uribe, Juan Manuel Battaglia, César Cueto, Esteban Barberón, José Daniel Van Tuyne, Ricardo

\footnotetext{
5 Según la edición 1319 de la Revista Semana, en febrero del 2007 el directivo del Deportivo Independiente Medellín (DIM), Rodrigo Tamayo (acusado por el revisor fiscal del club, Juan Bautista Ávalos, de ser socio de Pablo Escobar y del paramilitar Diego Murillo Bejarano 'Don Berna') vendió de manera irregular el control del equipo por 7.800 millones de pesos a "Sueños del Balón"; una sociedad en la que están los reconocidos entrenadores Francisco Maturana, Hernán Darío Gómez, Víctor Luna y Juan José Peláez. Dada esta historia del DIM, una la de las tareas de la Fiscalía será determinar si realmente el equipo fue vendido o si fue una simulación.
} 


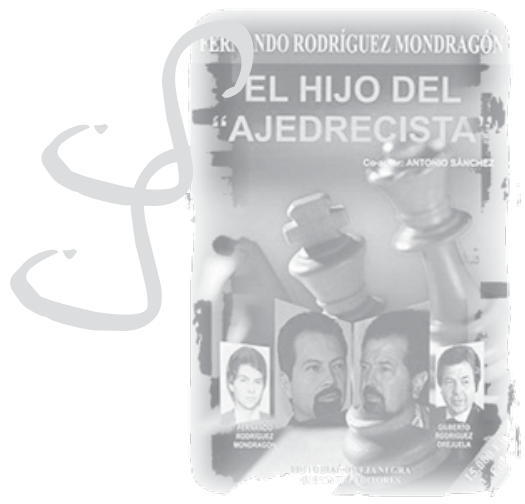

Gareca, Guillermo La Rosa, Julio César Falcioni, entre otros, quienes ayudaron a crear una liga de fútbol de primer nivel y de la talla de la argentina y brasilera, lo cual hizo recordar a los hinchas colombianos la límpida y gloriosa época de El Dorado 6 cuando sin capitales oscuros el balompié nacional brilló con luz propia. Un buen ejemplo de ese refulgir deportivo de la década del cincuenta del siglo pasado es el Club Los Millonarios de Bogotá que se dio el lujo de ser considerado "el mejor equipo del mundo" al vencer al encopetado Real Madrid en su propio estadio ${ }^{7}$.

Pero el libro del heredero del Clan de Cali no alude solo a la influencia monetaria de los Rodríguez Orejuela a nivel de clubes; también relata que treinta años después de El Dorado los dineros mal habidos alcanzaron, incluso, al "tótem nacional", la Selección Colombia que, pese a contar con la mejor camada de futbolistas de todos los tiempos (que nos llevaron a tres mundiales consecutivos) recibió "una manita" de "Los amos del juego"8 que llegaron al exceso de sobornar a un árbitro para que en un juego amistoso disputado en Manizales en marzo de 1994, previo al mundial de Estados Unidos, favoreciera al equipo tricolor que, con esa inusual ayu- da extra, logró empatar el partido ante el Flamengo de Brasil (que ganaba 3 a 1) y "recobró así la confianza necesaria para afrontar la Copa Mundo que se avecinaba"9. Meses después, mientras la escuadra nacional esperaba su primer partido mundialista en Los Ángeles (California), el otro Cartel, el de Medellín, influiría en el entorno de la Selección cuando, a través de casetes y llamados telefónicos a su Director Técnico, Francisco Maturana, le aseguraron que protegerían y apoyarían al conjunto patrio ante las amenazas de un grupo autodenominado "Lifucol" (Limpieza del Fútbol Colombiano) que textualmente le exigía a 'Pacho' Maturana que "echara del equipo a varios jugadores que pertenecían a los carteles de la

\footnotetext{
6 Romántica década del balompié colombiano (situada en los cincuenta) que se caracterizó por la masiva llegada de jugadores del sur del continente como Alfredo Di Stéfano, Adolfo Pedernera y Néstor Rossi que, aprovechando huelgas futbolísticas como la ocurrida en Argentina, emigraron a Colombia donde les esperaban mejores sueldos y una afición que los acogió con entusiasmo y cordialidad.

7 El 31 de marzo de 1952 Millonarios, en el marco de "Las bodas del Real Madrid", venció 4 a 2 al club madrileño en el estadio Chamartin de la capital española. "Millonarios el mejor equipo del mundo" y "lo más grande que ha visto Madrid: Millonarios de Bogotá" fueron, según Jorge E. Peña, algunos de los titulares de la prensa ibérica. Jorge E. Peña et al. Millonarios: 50 años de gloriosa historia. Bogotá: Edición privada, 1996.

8 Juan Ignacio Rodríguez. Los amos del juego. Bogotá: Periódicos y Revistas, 1989.

9 Testimonio dado por Fernando Rodríguez Mondragón, hijo de Miguel Rodríguez Orejuela, el 7 de septiembre de 2007 a la W Radio de Caracol, en el que narró que pese a la calidad del equipo nacional, el Cartel de Cali proporcionó recursos para hacerle el camino más expedito hacia sus metas deportivas.
} 
droga"10; Ia amenaza hacía clara alusión a la comprobada amistad de Escobar y sus socios con los futbolistas paisas ${ }^{11}$ que militaban en el onceno colombiano.

Fue tal el revuelo originado por el libro (y por las comprometedoras fotografías que publica $)^{12}$ que en casi todos los medios de comunicación nacionales (tanto impresos, audiovisuales y electrónicos) hubo avalancha de comentarios, correos y opiniones al aire de lectores, corresponsales, televidentes y oyentes que exigían que clubes criollos como el América de Cali, Atlético Nacional y Millonarios devolvieran "las estrellas"13 que habían cosechado por obra y gracia de la bonanza marimbera y cocalera. La paradoja subyacente en ese angustioso pedido es que si se hiciera caso de él, tendríamos que borrar de un plumazo el mejor periodo del fútbol colombiano en lo que respecta a su faceta internacional (7 subcampeonatos y un título de la Copa Libertadores de América; el título de la Copa América de selecciones en el 2001 y las clasificaciones a los mundiales de Italia 90, Usa 94 y Francia 98).

Un corolario de esos episodios noticiosos y la mejor ilustración de los mismos es la orden de captura, proferida por la Fiscalía General de la Nación el pasado 14 de septiembre de 2007, contra el alcalde de Cúcuta, Ramiro Suárez Corso, quien es acusado de determinar el asesinato de un ex funcionario de la alcaldía y es señalado de tener nexos con grupos sobrevivientes de las desaparecidas Autodefensas Unidas de Colombia (AUC) ${ }^{14}$ y narcotraficantes del corredor limítrofe colombo- venezolano. Ante esa disposición del ente acu- sador, cientos de cucuteños se apostaron en las afueras del Palacio Municipal y con arengas hacia el Fiscal General de la Nación y otros contradictores del mandatario local y entonando cánticos del "doblemente glorioso" Club Cúcuta Deportivo, impidieron que el sindicado fuera sacado del edificio y trasladado a Bogotá por detectives del Cuerpo Técnico de Investigación. Y como si fuera poco, en el partido que el club "motilón"15 afrontó 48 horas después del "espontáneo bloqueo ciudadano" contra la disposición de arresto al burgomaestre de la frontera, el delantero Lionard Pajoi celebró a rabiar un gol levantando la camisa roja que ha distinguido al alcalde en sus correrías políticas, en claro agradecimiento por el desmesurado -y sospechoso- apoyo económico que el dirigente municipal ha dispensado al equipo de fútbol de la ciudad que ganó

\footnotetext{
10 Rafael Mendoza. Tras el equipo de ensueño: la increíble historia de la Selección Colombia. Armenia: Kinesis, 2003.

11 Nombre dado a los habitantes de Antioquia, cuya capital es Medellín.

12 Gente del mundo de la farándula y de la política nacional aparecen en decenas de fotografías publicadas en la obra literaria del hijo mayor de Gilberto Rodríguez Orejuela; pero la foto más impactante es en la que aparecen algunos miembros del clan de Cali con Hugo Santelli, ex presidente del club River Plate y ex ministro de Hacienda de Argentina.

13 En algunos países, incluida Colombia, la expresión "estrella" denota la obtención del título de liga de fútbol.

14 Organización paramilitar creada por el asesinado Carlos Castaño Gil y bautizada con la sigla AUC que pretendió agremiar, con relativo éxito, a todos los grupos contrainsurgentes de Colombia.

15 La etnia motilona es el grupo indígena que inspira el nombre popular con que se distingue al Club Cúcuta Deportivo.
} 
-en la administración de Suárez Corso- la categoría promocional y luego el torneo nacional llegando, incluso, a semifinales de la Copa Libertadores de América.

Ante tales evidencias periodísticas que relacionan al fútbol colombiano con la exportación y comercialización ilegal de alucinógenos, realizada por bandas organizadas, aflora la siguiente pregunta: ison esas noticias hechos aislados del fenómeno narcotraficante o son una pequeña muestra del maridaje entre el fútbol colombiano y los carteles de la droga? Una simple mirada a la realidad nacional haría obvia la respuesta, sin embargo apliquémosle el beneficio de la duda al formular los siguientes interrogantes: ¿qué razones habría para que un deporte tan popular -y a la vez prestigioso- como el balompié hiciera alianza con el negocio de la coca? ¿Cuál es la explicación para que hombres con fortuna económica -como los ex futbolistas mencionados- se asocien con narcotraficantes? ¿Es ese, en caso de ser cierto, un fenómeno netamente colombiano? Así mismo ¿qué posibles beneficios encuentran los carteles de la droga en el fútbol? ¿Desde cuando lo tienen en la mira y/o desde cuando han entablado una íntima relación con él? ¿Qué tanto han facilitado, por acción u omisión, los políticos, los organismos de control y los potentados económicos este indebido pacto? ¿Es esto un simple show massmediático? No obstante, más allá de la crónica periodística y del dato histórico, brotan tres preguntas adicionales: ¿Cuál es la relación entre drogas, tráfico y deporte de alto rendimiento? ¿Acaso esos elementos se encuentran en la adicción y el doping? ¿Es posible que la llegada de los futbolistas al comercio de psicotrópicos se de por vía del propio consumo?... son dudas que asaltan al colombiano promedio, que no van a ser absueltas en este artículo, pero que urgen ser tratadas con la mirada compresiva de la academia.

\section{Primeros pases que condenan}

Nuestro país se ha caracterizado por la proclividad al ostracismo de sus propios ciudadanos, sea por causa de la violencia política (en calidad de refugiados o exiliados), por causa de la escasez de oportunidades económico- profesionales (los que migran como ilegales a Estados Unidos y España, sobre todo; más los "cerebros fugados" que se establecen en países que apoyan y valoran sus capacidades intelectuales) y los que, por no saber otro oficio, por desesperación o por tradición familiar, salen a delinquir en patrias ajenas o llevan en sus cuerpos unos gramos de droga que les alivie sus dramáticas situaciones $^{16}$. Pero a esos tipos de salida habría que agregar una más: la ligada a los acuerdos bilaterales de extradición que tiene el gobierno colombiano con varios países amigos y cuyo caso paradigmático

\footnotetext{
16 La premiada película María llena eres de gracia (2004) del director Joshua Marston hace una buena ambientación de las motivaciones de los correos humanos del narcotráfico ("las mulas" en el argot periodístico) a la hora de arriesgarse a llevar un cargamento en el interior de sus estómagos o en su equipaje.
} 
- son esas noticias hechos aislados del fenómeno

narcotraficante 0 son una pequeña muestra del maridaje entre el fútbol colombiano y los carteles de la droga?

es el acuerdo suscrito entre Colombia y Estados Unidos en el que cerca de 750 nacionales han sido enviados a juicio ante las cortes yanquis por iningún norteamericano entregado a la justicia nuestra! ${ }^{17}$

Pues bien, los expedientes judiciales dicen que el 15 de noviembre de 1984 es la fecha en la que fue extraditado el primer colombiano a la patria del Tío Sam. Dicho compatriota fue Hernán Botero Moreno, acusado y condenado a 30 años de cárcel por lavar 52 millones de dólares. El Doctor Botero era presidente y gerente del Club Atlético Nacional y es "recordado en una gran foto en la que exhibía un puñado de dólares durante un partido de fútbol que perdía su onceno"18. Una buena ilustración del aire fraternal que envolvía a los narcos con la dirigencia del balón pie de entonces, se expresa en la decisión de la Dimayor que, luego de esa extradición, ordenó suspender los partidos de la fecha ien señal de duelo! Años después, frente al tribunal estadounidense, el dirigente deportivo admitiría la presencia de "dineros calientes" en el balompié antioqueño y del país en general. Dicha delación ratificaría la silenciosa entrada de la organización de Pablo Escobar en la administración de los dos clubes profesionales de Medellín y en la presidencia del otro club de Antioquia: el Envigado Fútbol Club que, en 1991, fue el primer equipo nacional que, sin participar en otros torneos promocionales, ganó el campeonato de la segunda división y ascendió a la categoría élite del fútbol en Colombia. No sería extraño que, a raíz de la exportación judicial de Botero Moreno ${ }^{19}$, el Cartel de Medellín (nombre con el que los organismos de policía de USA bautizaron a la banda de Escobar) firmara todos sus comunicados con el rótulo de "Los Extraditables", cuyo tenebroso lema rezaba: "Preferimos una tumba en Colombia a una celda en Estados Unidos".

Por todos es sabido que las matas de Erythroxylon coca son oriundas de América y que las plantas de marihuana y de la herbácea amapola se dan con prodigalidad en las selvas amazónicas y en altiplanicies andinas ${ }^{20}$; pero lo que casi nadie

17 En el gobierno del actual presidente de los colombianos, Álvaro Uribe Vélez, se han extraditado -hasta septiembre de 2007- 670 compatriotas lo cual constituye un record si se compara con las cifras de extraditados en mandatos anteriores.

18 Fabio Castillo. Los jinetes de la cocaína. Bogotá: Editorial Documentos Periodísticos, 1987, p. 151.

19 Tampoco habría que olvidar que el segundo colombiano en ser enviado a manos de la justicia norteamericana fue Carlos Ledher, también socio de Pablo Escobar, quien tenía pocos vínculos con el fútbol, pero que también influyó para la creación del grupo de "Los Extraditables".

20 El arbusto de coca crece en terrenos que oscilen entre los 600 y los 1.500 metros sobre el nivel del mar y el cáñamo de cannabis sativa herbácea (marihuana) florece en casi cualquier ecosistema; mientras que la flor amapola, insumo principal de la heroína, requiere mayor altitud germinando de los 2.000 a los 3.500 m.s.n.m. 
conoce es que el procesamiento de esas plantas naturales con precursores químicos (éter etílico, acetonas, ácido clorhídrico, queroseno, etc., etc.) en laboratorios clandestinos no es un invento netamente colombiano al contar con antecedentes en Perú y Bolivia. De la misma manera, pocos se atreven a decir que los pioneros del negocio exportador fueron algunos chilenos que desarrollaron esa incipiente actividad en tiempos del dictador Augusto Pinochet ${ }^{21}$; claro que yéndonos más atrás deberíamos decir que el primer antecedente documentado, en el ámbito orbital, es el de las dos guerras del Opio que, a mediados el siglo XIX, enfrentaron a Inglaterra y Francia con China. Pero más allá de emitir juicios de valor culpando a éste o aquel país y más allá de jugar al historiador señalando la fecha exacta en la que se 'coronó' el primer embarque de droga en el primer mundo ${ }^{22}$, la pretensión de este artículo es relatar con sentido crítico algunos de los momentos de encuentro entre la práctica delincuencial de los narcos y el complejo ámbito del balón pie; intentando aportar pistas y elementos de juicio que ayuden a comprender con mayor justicia y menos prejuicio las posibles motivaciones que originaron el aparente contubernio entre el tráfico de alcaloides y drogas psicotrópicas, con el deporte más popular en Colombia y el mundo: su majestad el fútbol.

\section{América de Cali o la hegemonía valluna ${ }^{23}$}

La Corporación Deportiva América de Cali es la institución futbolera más antigua de Colombia: fue fundada en 1927, pero sus comienzos son para olvidar ya que de los llamados equipos grandes del país fue el último equipo en alcanzar una estrella en el torneo nacional; no obstante, desde aquel primer trofeo de campeón obtenido el 19 de diciembre de 1979, su racha de títulos no tiene parangón en el balompié criollo: América, la 'Mechita' como la llaman sus fervientes seguidores, cosecha la nada despreciable cifra de trece títulos en sus vitrinas, cinco de ellos alcanzados en forma consecutiva (de 1982 a 1986) y fue finalista de tres Copas Libertadores de América en línea (ediciones de 1984,

\footnotetext{
21 Federico Tatter et al. "DINA y Pinochet se financiaron con crimen organizado". En: http://www.voxpublica. org/derechos/archives/002761.html. Fuentes: Reporte Nizkor, Chile (Agosto, 2006) y Diario La Nación, Santiago de Chile (21 de mayo de 2006).

22 El filme La Virgen de los sicarios (2.000) del director Barbet Schroeder, basada en la obra de Fernando Vallejo, muestra cómo los narcotraficantes queman fuegos artificiales y pirotécnicos para celebrar la exitosa llegada de un embarque de drogas a EE.UU.

23 La expresión "valluno" alude a 'vallecaucano' que es el gentilicio de los nacidos en el departamento del Valle del Cauca, cuya capital es Santiago de Cali.
} 
85 y 86), hazaña solo lograda por el Boca Juniors de Argentina ${ }^{24}$. ¿La razón de tales éxitos deportivos? Cualquier vallecaucano respondería sin pensarlo dos veces: el abundante dinero invertido por la familia Rodríguez Orejuela en el equipo. De hecho, la plantilla de jugadores del club escarlata era de las más costosas del continente al contar con luminarias deportivas del cono sur entre las que destacaron Juan Manuel Bataglia y Roberto Cabañas (Paraguay), Julio César Falcioni y Ricardo Gareca (Argentina) y la súper estrella de los colombianos Willington Ortiz. El estelar elenco era dirigido por el director técnico más ganador de títulos en Colombia, el médico Gabriel Ochoa Uribe ${ }^{25}$ que, después de retirado de los bancos técnicos, aceptó abandonar el consultorio y regresar a su profesión deportiva para conducir al equipo caleño, luego de una jugosa oferta económica hecha por el presidente del club, 'Pepino' Sangiovanni, en 1979. En fin: el remozado club de principios de los ochenta fue conformado para ganarlo todo y la verdad sea dicha, ese propósito se consiguió; el América de Cali comparte predominancia con el capitalino club de Los Millonarios (que suma 13 títulos) y es una marca registrada en toda Suramérica. Así mismo, es el equipo más destacado por Colombia -en número de puntos- del prestigioso torneo surcontinental y ha sido el único de nuestro país en figurar en el cuarto puesto del ranking mundial de la Federación Internacional de Historia y Estadística del Fútbol (IFFHS) ${ }^{26}$. Un mito urbano ilustra la bonanza deportiva y económica de "los diablos rojos"27; se trata de aquel relato -muy popular en estratos bajos de Cali- que cuenta que Diego Armando Maradona alcanzó a vestirse de rojo y entrenar en Cascajal (sede del equipo), hasta que la negociación entre Boca Juniors y América se dañó porque el Barcelona de España puso más dinero por los derechos deportivos de la estrella argentina.

Pero esa historia dorada del equipo escarlata que tantos nuevos hinchas le granjeó, ya es cosa del pasado: actualmente el equipo se encuentra embargado por dos frentes; de un lado está la congelación de sus cuentas bancarias y la proscripción financiera por causa de la Lista Clinton que convierte a la razón social del club en
24 "La Maldición del Garabato" es, según sus miles de seguidores y simpatizantes, la culpable de que el equipo escarlata de la capital del Valle del Cauca no haya podido nunca alzarse con el trofeo sur continental de clubes. Dicho conjuro, proferido por un directivo desertor, se aplicaba-inicialmente- para los torneos locales, pero a raíz de la seguidilla de títulos nacionales, la maldición se desplazó hacia las copas internacionales en dónde el América, pese a haber disputado cuatro finales de la Libertadores (tres de ellas consecutivas) no ha podido subir al podio de campeón. Claro que, como dato curioso, muchos atribuyen la sequía internacional a razones ético- religiosas: el equipo del clan Rodríguez Orejuela no podrá triunfar hasta que no saque de sus arcas el "dinero maldito" de la droga y hasta que no elimine al diablo como blasón de su divisa.

25 El Doctor Ochoa Uribe acumula, como entrenador, 11 títulos de liga nacional: cinco con el Club Millonarios y seis con el Club América de Cali.

26 En medición hecha y publicada, en agosto de 1985, por parte de la IFFHS.

27 El mote de "Diablos rojos" deriva del escudo del equipo en el que aparece la figura de un Mefistófeles empuñando un tridente satánico. 


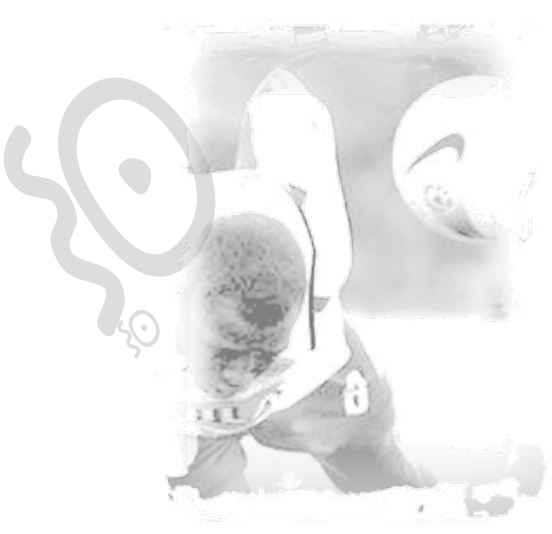

algo menos que un occiso comercial ya que cualquier depósito en sus cuentas de ahorro en Colombia y el mundo queda automáticamente congelado por el departamento del tesoro estadounidense, por lo que el equipo debe ser manejado con finanzas de barrio: todos los movimientos monetarios deben hacerse en efectivo y a nombre de personas naturales lo que estimula el ilegal ejercicio del testaferrato ${ }^{28}$. El otro secuestro financiero del equipo del Valle del Cauca es por cuenta de la justicia ordinaria colombiana que ha decidido que se practique extinción de dominio (expropiación policiva y administración estatal provisional) de empresas, compañías, medios de comunicación ${ }^{29}$, acciones bursátiles y de predios urbanos y rurales del conglomerado familiar presidido por Gilberto y Miguel Rodríguez Orejuela, capos del extinto Cartel de Cali, hoy en prisiones norteamericanas en virtud del tratado de extradición. Muchas de esas empresas y posesiones fueron declaradas como objeto de "lavado de activos" en lo que coloquialmente se denomina "lavanderías", cuya razón de ser -dicho también en jerga popular- "es servir como empresas fachada para blanquear dinero". Por tal razón, el club de fútbol ya no cuenta con los ingentes ingresos que le proporciona- ba el consorcio empresarial de los hermanos Rodríguez Orejuela y buena parte de sus patrocinadores (hoy inexistentes ya que ninguna firma se arriesga a aparecer en la camiseta de un equipo paria) están administrados por el Estado colombiano por intermedio de la Dirección Nacional de Estupefacientes.

Una coincidencia que emparenta el modus operandi de la banda de narcotraficantes de Cali con la de Medellín es que varios presidentes del club rojo de Cali, al igual que algunos dirigentes de los equipos de Antioquia, resultaron encarcelados por sus evidentes nexos con el mundo de las drogas ${ }^{30}$ : al jerarca escarlata Pedro Chang le fue dictada medida de aseguramiento y fue recluido durante algún tiempo en el calabozo de la Fiscalía por el cargo de enriquecimiento ilícito a favor de terceros; mientras que Juan

\footnotetext{
28 Modalidad usada con frecuencia por los narcotraficantes que, para alejar las sospechas de la ley sobre sus negocios ilícitos, consiguen que sus bienes y sus transacciones queden en manos y sean realizadas por terceras personas.

29 El Grupo Radial Colombiano (GRC) pertenecía a la familia Rodríguez Orejuela. Desde sus micrófonos algunos periodistas áulicos de Miguel y Gilberto Rodríguez Orejuela le hacían buena prensa a sus empresas; el caso más ilustrativo es el de "La Guerrilla deportiva", grupo de periodismo deportivo que obviaba la procedencia de dineros indebidos en el América de Cali, haciendo énfasis en sus contundentes triunfos futboleros.

30 Vale aclarar que una de las principales empresas manejadas por el Cartel de Cali era "Drogas la Rebaja"; cadena de droguerías ubicadas en medio centenar de municipios de Colombia. La paradoja implícita en esta circunstancia es evidente: un Cartel de drogas ilícitas (y que comercializa alucinógenos) tiene, a su vez, una empresa de fármacos terapéuticos.
} 
José Bellini ${ }^{31}$, presidente del América y de la Federación Colombiana de Fútbol, estuvo tres años tras las rejas por causa del inusitado aumento patrimonial que registró en sus finanzas y por la relación de su nombre en la contabilidad de los Rodríguez Orejuela. Otros presidentes del Club América y de la Fedefútbol que fueron investigados por sus presuntos nexos con "El Ajedrecista" son Oreste Sangiovanni, Carlos Puente ${ }^{32}$ y Álvaro Fina. Al respecto, Fernando Rodríguez dice en su libro: "Ese poder también se extendía a la Federación Colombiana de Fútbol cuando fue manejada por León Londoño Tamayo, amigo personal de los hermanos Rodríguez; Juan José Bellini, quien fue la mano derecha de Miguel Rodríguez; y Álvaro Fina, quien fue incondicional con los capos. Miguel llegó a tener cupos fijos en las selecciones Colombia, esto es que tenía derecho a sugerir jugadores, técnicos y médico"33.

Claro que la mafia narcotraficante del occidente colombiano no solo ha metido sus narices en el mundillo futbolero ya que tenemos noticia de sus incursiones en la orbita política; de hecho la principal crisis institucional de las últimas cinco décadas en Colombia surgió de la entraña del Cartel de Cali: "el Proceso 8.000"34, en el que se develó que la elección del presidente Ernesto Samper Pizano para el periodo comprendido entre 1994 y 1998 fue parcialmente auspiciada con dineros calientes de la mafia del tráfico de estupefacientes. A la postre el mandatario liberal fue exonerado por su juez natural: el Congreso de la República en un largo proceso que dejó serias dudas de legitimidad, pero que originó que medio centenar de políticos, periodistas ${ }^{35}$ y empresarios (principalmente vallecaucanos) fuera a parar a la cárcel en medio de una tempestad política que produjo ríos de tinta y estremeció la institucionalidad nacional: el presidente Samper se sustrajo de gobernar para dedicarse a su defensa; Estados Unidos le retiró la visa y no certificó a Colombia en la lucha contra el narcotráfico ${ }^{36}$, las cifras in-

31 El profesor Pedro Chang logró explicar sus negocios y salió de prisión el 28 de febrero del 2000; en tanto que Juan José Bellini estuvo apresado entre noviembre de 1995 y octubre de 1998. En esa fecha salió con libertad condicional.

32 Que hoy aparece como presidente vitalicio del equipo escarlata ya que nadie se expone a administrar al Club América, so pena de ser incluido en la Lista Clinton a la que Carlos Puente pertenece desde hace una década.

33 Fernando Rodríguez y Antonio Sánchez. El hijo del ajedrecista. Bogotá: Editorial Oveja Negra y Quintero Editores, 2007, p. 86.

34 Publicitado proceso judicial apenas superado por el actual escándalo que los medios de comunicación nacionales han llamado de la 'Parapolítica' (contubernio de paramilitares con funcionarios públicos y políticos en general e infiltración paramilitar en el gobierno y la función pública).

35 El periodista Alberto Giraldo fue la figura más conocida de los medios de comunicación que fue a prisión por culpa del "Proceso 8.000" y los periodistas deportivos Esteban Jaramillo, Rafael Araujo y Mario Alfonso Escobar "Mao" purgaron sentencia judicial por cuenta de cheques girados a su nombre por el Cartel de Cali.

36 Inequitativa fórmula estadounidense consistente en obviar la lucha contra el consumo interno para dedicarse a aprobar o reprobar (según estadísticas) las políticas nacionales de sus países aliados en materia de erradicación de cultivos ilícitos y persecución de las estructuras de procesamiento, distribución y comercialización de la droga. El premio al esfuerzo de cada país se ve recompensado con regulares desembolsos económicos y con la asistencia técnico- militar y el castigo es la supresión de esos aparentes beneficios. 
flacionarias y de desempleo aumentaron; el país decreció en su macroeconomía (aumentó considerablemente el precio del dólar y disminuyó el PIB y el porcentaje de exportaciones, entre otros indicadores) ${ }^{37}$ y se sucedieron una serie de asesinatos de figuras políticas de primer nivel ${ }^{38}$ que hicieron salir a flote la casi comprobada conspiración para derrocar al sospechado presidente de turno. De igual manera, no podemos olvidar la cruenta guerra librada entre sí por los carteles colombianos en procura de hacerse a las rutas y los mercados internacionales de la droga. El nefasto saldo de esa descarnada batalla campal fueron los atentados selectivos que plagaron de sicarios y mercenarios las calles de las ciudades de Medellín y Cali y las cobardes bombas detonadas en una y otra ciudad contra empresas de ambas organizaciones delincuenciales en las que perecieron cientos de inermes e inocentes compatriotas.

Volviendo al campo de juego, podríamos decir que el mejor colofón para significar lo que fue el Cartel de Cali nos lo proporciona la dedicatoria de triunfo que el delantero Anthony "el Pipa" de Ávila hizo en vivo y en directo por la televisión nacional a su "Patrón" recluido en la penitenciaria La Picota de la capital de la República. El afectuoso saludo fue difundido al país en franja prime time y ocurrió en un día de fiesta patria: el 20 de julio, que es la fecha en la que se rememora el grito de Independencia en Colombia. En dicho saludo se veía que el jadeante futbolista, que acababa de marcar el tanto que clasificó a la Selección Nacional al Mundial de Francia
98, ofrecía su importante gol al "Ajedrecista" Gilberto Rodríguez Orejuela -capo del cartel caleño- recién capturado por el Bloque de Búsqueda de la Policía Nacional ${ }^{39}$. Por esa razón, el gobierno estadounidense le cancelaría la visa al "Pitufo" de Ávila que no pudo volver a enfundarse la camiseta del Metro Stars de Nueva York en el que militaría hasta ese mes de julio de 1997. No obstante, el puntero que se preocupó por pegar -en todos los partidos que jugó con el América- una cinta blanca que tapaba el diablo del escudo americano, sería recomendado -después del episodio de la dedicatoria- por los "señores de la droga" a sus 'amigos' del Ecuador para que fuera recibido con todos los honores en el fútbol bananero ${ }^{40}$ en donde tuvo gran suceso deportivo. Otros compañeros de generación y de equipo de Anthony de Ávila no corrieron la misma suerte: el lateral Wilson Pérez fue arrestado, el 16 de octubre de 1995, en el aeropuerto Ernesto Cortizos de

\footnotetext{
37 Percepción del autor que se basa en la avalancha de columnas de opinión e informes económicos de prensa que confirmaban esa dramática situación político- financiera del país en épocas del "Proceso 8.000".

38 Elizabeth Montoya de Sarria (conocida por la prensa como "la monita Retrechera") fue la primera víctima. Se presume que su violenta muerte se debió a una comprometedora fotografía que relacionaba al presidente Samper con personajes de oscuro pasado. Luego, comandos sicariales acabaron con la vida del general Fernando Landazábal Reyes y del político conservador Álvaro Gómez Hurtado.

39 Grupo élite de la Policía Nacional conformado con el objeto de atrapar a los capos de los narcóticos.

40 La asociación del país ecuatoriano con su principal renglón de la economía es apenas lógica
} 
Barranquilla al intentar sacar 171 gramos de cocaína en su equipaje, Willington Orti $z^{41}$ fue incluido en la lista Clinton y por ello frustró su deseo de ser director técnico ya que por esa situación nadie lo contrata y Albeiro "El Palomo" Usurriaga fue asesinado en el 2004 -en un presunto ajuste de cuentas del paramilitarismo- en su barrio natal de Cali cuando jugaba dominó, un popular juego de mesa de los litorales colombianos.

\section{Atlético Nacional y el predominio paisa}

A su vez, la ciudad de la "eterna primavera" a la que Boogie "el aceitoso" no quiso venir por físico temor ${ }^{42}$, alberga al primer equipo en ganar un partido en el torneo de fútbol colombiano ${ }^{43} \mathrm{y}$ al primero del país en alzarse con la codiciada Copa Libertadores de América; nos referimos al Atlético Municipal, hoy rebautizado como Club Atlético Nacional. El Nacional tiene cosidas diez estrellas en su escudo y ha ganado, aparte de la Libertadores, cuatro campeonatos internacionales por lo que sus hinchas lo denominan "el rey de copas". Sin embargo, algunas de sus victorias han estado empañadas por la sospecha nunca comprobada de influencia narcotraficante en los resultados finales. Una anécdota que resulta reveladora de tal aseveración es la que relata cómo el "verde de la montaña" tuvo que repetir, en la Copa Libertadores de 1989 (año en que fue campeón), un partido ante la acusación de soborno mafioso a árbitros internacionales ${ }^{44}$ y cómo la plaza antioqueña (en especial, el estadio Atanasio Girardot) fue vetada por jueces, equipos rivales y veedores internacionales ante las presuntas amenazas de muerte emitidas por $\mathrm{Pa}$ blo Escobar y sus lugartenientes a todo aquel que se atravesara en el camino al triunfo de "los puros criollos"45. Al final el club dirigido por Francisco Maturana tuvo que conformarse con jugar 'exiliado' en el estadio El Campín de Bogotá en dónde René Higuita fue la gran figura al atajar cuatro penaltis que facilitaron que él y sus

41 El "Viejo Willy" se disputa con Carlos "El Pibe" Valderrama el honor de ser el mejor jugador de todos los tiempos del fútbol colombiano.

42 Ver la simpática tira cómica del caricaturista argentino Roberto Fontanarrosa en la que el célebre mercenario declina "un trabajo" luego de que le dicen dónde debe realizarlo: la ciudad de Medellín, Colombia.

43 Esto sucedió el 15 de agosto de 1948, año en que se inauguró el torneo local, cuando Rafael Serna anotó el primer tanto del Municipal ante el equipo de la Universidad Nacional.

44 El silbato argentino Carlos Espósito le contó al periódico Cronista Comercial (13/04/1990) de Argentina que fue amenazado de muerte en Medellín cuando dirigió un partido de la Copa Libertadores de 1989; año en el que Atlético Nacional fue campeón. Así mismo, el pito uruguayo Juan Daniel Cardelino denunció que, el 29 de agosto de 1990, intentaron sobornarlo para que influyera en el resultado del partido que disputaron Nacional y Vasco da Gama. El partido, ganado por Nacional, debió repetirse y todos los estadios de Colombia estuvieron suspendidos, para eventos internacionales, por tres meses.

45 El mote de verde de la montaña salta a la vista al ver el uniforme del Atlético Nacional y relacionarlo con "la tacita de plata" que es la metáfora geográfica que mejor describe a Medellín, ciudad enclavada en medio de montañas. Así mismo, el apelativo de "puros criollos" se dio en las décadas del 80 y el 90 cuando se puso de moda el slogan "Hecho en Medellín" que fue replicado por el club antioqueño que se negó a contratar extranjeros. 


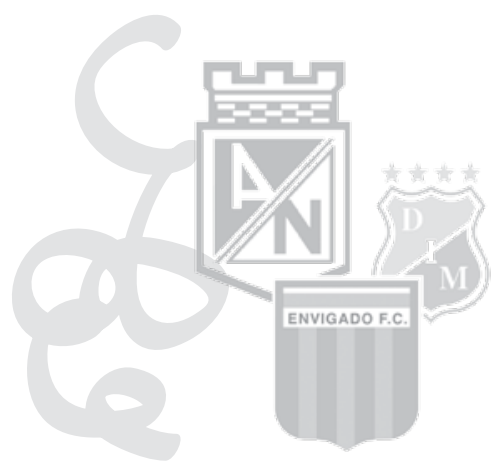

compañeros accedieran a la esquiva gloria suramericana de levantar el trofeo de clubes más importante de América.

Pero la "prueba reina" que enlaza al clan de Medallo46 con el mundo de los guayos es el libro escrito desde la cárcel por Roberto "El Oso" Escobar, hermano mayor de "El Patrón" y confeso narcotraficante que además es investigado por el asesinato del ministro de Justicia, Rodrigo Lara Bonilla, el 30 de abril de 1984. El mayor de los Escobar pagó un tiraje de 5.000 ejemplares en los que revela datos íntimos de su vida, de sus parientes y de sus amigos, socios y allegados involucrados en tráfico de estupefacientes. La trama literaria de Mi hermano Pablo transcurre en la Cárcel 'La Catedral', penitenciaría construida bajo los requerimientos geográficos, estratégicos y arquitectónicos ordenados por "el padrino de los pobres" para así torcerle el cuello al cisne jurídico. Maniobra que le permitiría acogerse de manera espuria a la ley colombiana sin exponerse a una captura de los marines norteamericanos que siempre lo tuvieron en la mira; cuestión llena de ilegalidad y de paranoia y que a la postre provocó que el hombre más buscado del planeta se evadiera -en junio de 1992- con su guardia personal de dicho centro de reclusión apenas sintió que el gobierno de César Gaviria "podía traicionarlo" entregándolo a agentes de la justicia estadounidense. En esa versión de los hechos de Roberto Escobar, se cuenta como el Cartel de Medellín organizaba frecuentes partidos del fútbol contra jugadores profesionales de las plantillas de los tres equipos de Antioquia: el "Poderoso" Deportivo Independiente Medellín, el Atlético Nacional y el Envigado Fútbol Club. "Los partidos eran interminables y duraban hasta que Pablo quisiera y ello ocurría cada vez que el equipo del Cartel anotaba el gol del empate o de la victoria (...) Escobar era buen jugador, le pegaba durísimo al balón. El siempre se hacía adelante y se enfundaba la camiseta número 9". Según "El Osito", después de esos convites "se repartía dinero entre futbolistas y técnicos y se hacían recomendaciones deportivas para que los tres equipos de Antioquia siempre estuvieran en la punta del campeonato" 47 .

Las infidencias relatadas en 168 páginas por Roberto Escobar (ciclista retirado y ex- entrenador del team nacional) se corresponden con los escándalos de prensa suscitados por las frecuentes visitas de celebridades del balón como René Higuita y Leonel Álvarez a la ficticia prisión de Es-

\footnotetext{
46 Apócope de Medellín que tiene una variante perversa: "Metrallo", que remite a la aguda violencia vivida en la ciudad durante el imperio de "Los Extraditables".

47 Roberto Escobar. Mi Hermano Pablo. Ciudad no mencionada: Quintero Editores, p. 196 y 198.
} 
cobar, desde la cual seguía orquestando sus fechorías. Imágenes del célebre portero y de otros compañeros suyos a bordo del jeep que los conducía desde el anillo externo, controlado por el Ejército, hasta la puerta de los guardianes al servicio de Pablo Escobar, fueron repetidas hasta la saciedad por los medios colombianos y replicadas en el mundo entero. Así se sellaba el contubernio entre los "Jinetes de la cocaína" y "los dueños del balón"48; matrimonio mal avenido que inició cuando el jefe del cartel de Medellín construyó y techó varias canchas de fútbol del Valle del Aburrá (zona metropolitana de Medellín), cuando auspició con fraudulenta generosidad a muchos equipos de fútbol locales y cuando patrocinó la presencia de un equipo nacional de ciclismo ${ }^{49}$-el otro deporte nacional- en la principal prueba por etapas del mundo: el Tour de France ${ }^{50}$.

Sin embargo, el clímax de la influencia del negocio de narcóticos en el deporte colombiano se palpó en 1988 cuando el juez Armando Pérez fue secuestrado y apareció, al cabo de 20 horas, con un mensaje de sus captores que advertían que "si los árbitros mantenían una conducta parcializada, algunos de ellos podrían ser 'borrados'..."51. Ante esa cruda amenaza el gobierno nacional, a través de su Ministro de Educación, Manuel Francisco Becerra Barney ${ }^{52}$, empezó a presionar a la Dimayor y sus abonados, los clubes, para que cumplieran con lo establecido por la ley en cuanto a la rendición y depuración de cuentas financieras y en torno a la exigencia de garantías mínimas (laborales, de patrocinio, de logística de los

egún "El Osito", después de
esos convites "se repartía di-
nero entre futbolistas y técni-
cos y se hacían recomendaciones
deportivas para que los tres equipos
de Antioquia siempre estuvieran en
la punta del campeonato"

partidos, etc., etc.) para el buen desarrollo del espectáculo. Se optó por aceptarle la renuncia al presidente del ente de clubes colombianos (León Londoño Tamayo) y se eligió a un dirigente destacado por su pulcritud empresarial (Álex Gorayeb) a quien le tocó la desdicha de suspender el torneo nacional a raíz del asesinato del árbitro Álvaro Ortega en Medellín luego de un derby entre el equipo de los amores del Cartel de Cali, el América, versus el preferido por la organización de Escobar, el Atlético Nacional. El partido terminó en tablas por lo que, según el Diario El Co-

\footnotetext{
48 José Cipriano Ramos Valencia. Colombia versus Colombia: 50 años de fútbol profesional y violencia política. Bogotá: Intermedio Editores, 1998, p. 140.

49 En los cócteles bogotanos todavía se escucha la anécdota que relata cómo nuestros pedalistas cargaban gramos de cocaína en los tubulares y los marcos de las bicicletas que llevaban como instrumentos deportivos a las carreras europeas.

50 Fabio Castillo, op. cit., p. 162.

51 Jorge y Juan Guillermo Ruiz. Historia del fútbol profesional colombiano. Bogotá: Edición exclusiva de El Espectador, 1999, p. 96.

52 Quien debió declararse impedido ya que tiempo después resultaría detenido en el marco del Proceso 8.000.
} 
Iombiano (16/11/1989), "fue desempatado a tiros". Ese año, en el que el América de Cali punteaba, el título fue declarado desierto. El otro hecho, en el que vuelven a aparecer drogas y fútbol, que sacudió a la opinión pública mundial ocurrió el 2 de julio de 1994: la muerte violenta del antioqueño Andrés Escobar, defensa central de la selección Colombia, que -cuando aun no había terminado el mundial gringo ${ }^{53}$ de ese año- fue ultimado a balazos a la salida de una discoteca medellinense, por la ráfaga criminal de Humberto Muñoz Castro, un dolido escolta vinculado con apostadores y narcotraficantes, que le cobró al carismático futbolista el autogol que cometió en la Copa Mundo de Usa 94.

Otros futbolistas que repitieron el sino trágico del "gentleman" Andrés Escobar fueron Omar "El Torito" Cañas quien en febrero de 1993 fue asesinado por pistoleros del narcotráfico (Briceño, 98: 40) y Felipe 'Pipe' Pérez, un ex futbolista profesional que formó parte de la deslumbrante Selección juvenil colombiana que participó en el Suramericano de Asunción del Paraguay en 1985. El volante de armado fue abatido en septiembre de 1996, después de salir de prisión y soportar acusaciones que le señalaban como perteneciente a la banda mafiosa de Escobar (Ramos, Op. cit., p. 148). De igual manera, desde 1980, cerca de diez dirigentes de los tres clubes profesionales de la región paisa terminaron sus existencias por culpa de sus vínculos con el tráfico de sustancias alucinógenas, siendo el caso más dramático el del Envigado Fútbol Club que pasó de ser algo así como "la caja menor de

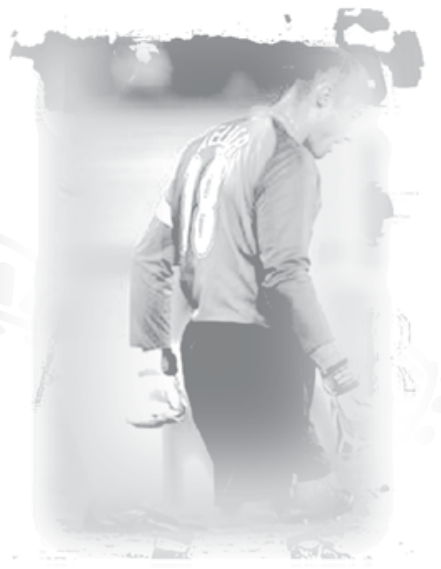

Escobar" a la temible "Oficina de cobros de Envigado" que está al servicio, hoy día, de paramilitares como alias "Macaco" (Carlos Mario Jiménez). Algunos directivos del fútbol antioqueño que llenaron los obituarios funerarios fueron: Pablo Correa Ramos, directivo del DIM; Octavio Piedrahíta, ex propietario de Nacional y el Deportivo Pereira; Carlos Arturo Mejía Gómez, del Comité Organizador del Suramericano Juvenil en Pereira ( + en 1986); Arquímedes Victoria, secretario de la Liga Metropolitana de Fútbol (1988); Germán Mejía Arango, dirigente de Manizales (1990); Gustavo Upegui y Octavio Velásquez, presidente y ex gerente, respectivamente, del Envigado Fútbol Club (2006). Para colmo de males digamos que en medio de esa tanda de muertes criminales el estelar arquero René Higuita fue a parar a la cárcel, en 1993, por mediar en la negociación de un secuestro con narcotraficantes y el mediocampista de El Nacional y la Selección, Diego Osorio, experimentó una situación similar al ser detenido, en 2003, al intentar ingresar unos gramos de coca en EE.UU.

53 Gringo es equivalente, en Colombia, a estadounidense. 
Cerramos este acápite diciendo que tal como aconteció con el clan de Cali, Pablo Escobar y sus muchachos influyeron dramáticamente en la política nacional: en 1982 el mismo capo resultó elegido a nombre del tradicional Partido Liberal Colombiano, en la suplencia de un escaño de la Cámara de Representantes y años más tarde, ya en la delincuencia explícita, se ofreció a pagar la deuda externa si el gobierno nacional le juraba no extraditarlo a los Estados Unidos. De igual manera, además del asesinato del ministro Rodrigo Lara Bonilla en 1984, Escobar segó la vida de importantes personajes de la vida nacional como la del director del periódico El Espectador, Guillermo Cano (asesinado en diciembre de 1986), quien en valientes editoriales venía denunciando los delitos de "El Patrón" y había señalado la perniciosa infiltración de la mafia en varios sectores de la sociedad colombiana, incluido el ámbito futbolístico. Tres años después del magnicidio periodístico, la sede del rotativo bogotano fue dinamitada. Fue por esa época que el jefe del Cartel de Medellín inauguró un régimen del terror sustentado en los bombazos y en los asesinatos selectivos perpetrados por su ejército de sicarios. La policía Nacional debe recordar con pavor ese tiempo ya que el gángster de las drogas ofrecía "cinco millones por cada policía muerto y dos por cada herido". Era tanta la ambición de Pablo Emilio Escobar Gaviria, que no pudo resistirse a la codicia del poder político y terminó asociándose -en 1989con un candidato a la presidencia de la República que resultaba prometedor: Al- berto Santofimio Botero; sin embargo, la calculadora mente del capo de las drogas de Medellín sabía que aun debía eliminar un duro escollo, el que representaba el candidato presidencial del liberalismo, Luis Carlos Galán Sarmiento, quien cayó bajo las balas asesinas de los matones de Escobar el 18 de agosto de $1989^{54}$.

\section{Millonarios y Santa Fe: el centro se hace periferia}

Colombia suele definirse como un país de regiones y en cierta medida acéfalo ${ }^{55}$; es decir, sin centro ni capital. No obstante desde la Independencia el centralismo ha predominado -con escasas interrupciones- con sus aciertos, sus vicios y limitaciones y por ese sistema de gobierno, entre otras cosas, puede afirmarse que se perdió la provincia de Panamás6. Dicha falta de cabeza es la que hizo afirmar a Daniel Pecaut que en nuestro país existía "modernismo sin modernidad"57, fórmula que se patentiza en las contradictorias

\footnotetext{
54 Virginia Vallejo. Amando a Pablo, Odiando a Escobar. Bogotá: Grijalbo, 2007, p. 45.

55 Francisco Leal. La inseguridad de la seguridad, Colombia 1958-2005, Bogotá: Planeta, 2006, p. 15.

56 La principal consecuencia del conflicto civil colombiano que enfrentó, a finales del siglo XIX y comienzos del XX, a liberales contra conservadores, mejor conocido como "La guerra de los mil días" fue la separación de la provincia de Panamá en noviembre de 1903.

57 Daniel Pécaut. Colombia: violencia y democracia, reproducido en Guerra contra la Sociedad. Bogotá: Planeta, 2001, p. 89.
} 


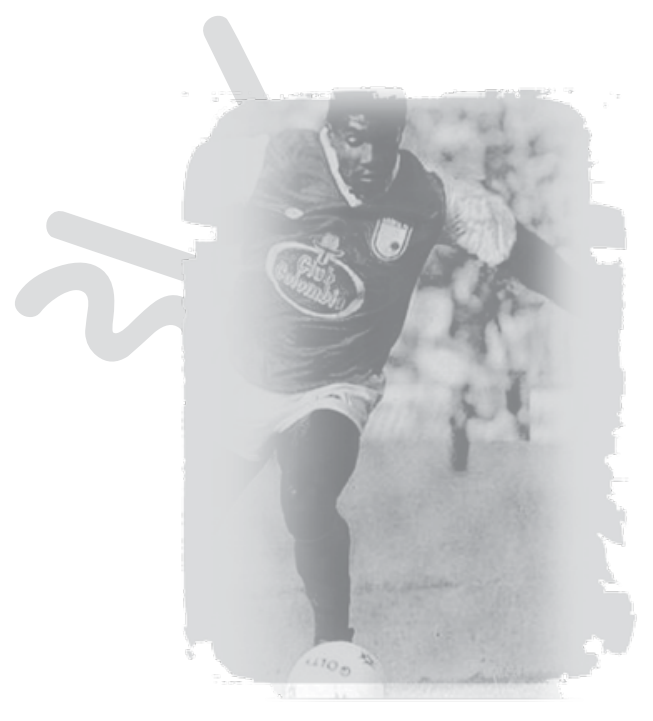

maneras de llamar a nuestra ciudad capital que unas veces es ensalzada como "una de las más inseguras del mundo", pero también es vista como la del "español mejor hablado"; que en oportunidades aparece rotulada como la de "mayores índices de indigencia", pero es reconocida como "la Atenas Suramericana" siendo no hace mucho distinguida como "la Capital Iberoamericana de la Cultura" y como la merecedora del Premio León de Oro de la Bienal de Venecia 2007 y designada como "Capital mundial del libro", entre otros premios y reconocimientos... pues bien, por estos días Bogotá DC., es Ilamada "la Casa de la Selección Colombia" (dignidad que se disputó con BarranquiIla) y es la morada de siempre de los dos equipos más tradicionales del país: Independiente Santa Fe y el Club Los Millonarios que, como un recuerdo indeleble de una nación que a lo largo del siglo XX se desangró por la lucha bipartidista, mantienen presente en el recuerdo colectivo de los cachacos ${ }^{58}$, los colores rojo y azul y la antigua pugnacidad de los partidos liberal y conservador, respectivamente.
Decir que estos clubes han tenido una historia fulgurante es verdad de PerogruIlo; los dos fueron los primeros campeones de la liga nacional y actuaron como protagonistas principales de El Dorado y los dos equipos tuvieron en sus filas a rutilantes figuras del balón venidas de todas las latitudes del mundo; no obstante su actualidad es triste y dista mucho de los lustrosos años de gloria de las décadas del 50, 60 y 70: Millos no alza la copa nacional desde 1988 y Santafecito lindo desde $1975^{59}$. Un indicativo de la precaria situación futbolística de los dos clubes en el último tiempo es que ahora se les ve pasando apuros para clasificar a semifinales cuando antes llegar a esa instancia era cosa natural; hoy Millonarios y Santa Fe no cuentan con las costosas nóminas de jugadores que caracterizaron la época de los carteles de la droga: ya no inspiran el respeto de antaño y el estadio El Campín no es visto como el lugar inexpugnable de los cincuenta ... Empero, no debe hacerse una lectura a priori de estos datos porque se puede llegar a conclusiones equivocadas como la que dice que los 'embajadores' y los 'cardenales' no gozaron de los atajos e inescrupulosas bondades deportivas ofrecidos por la mafia y por ello no cosecharon más títulos.

\footnotetext{
58 Cachaco es sinónimo de andino, de "gente del interior", de habitante no costeño; de persona lejana al mar. 59 Millos es el diminutivo de Millonarios y "los embajadores" y "los albiazules" son sus motes de antaño. A su vez, Santafecito lindo y los 'Cardenales' son los nombres populares del onceno albirrojo.
} 
Nada más alejado de la realidad: ambos clubes bogotanos fueron objeto de inversiones narcotraficantes así sus resultados no hayan resultado tan halagüeños como los vividos por los conjuntos de Antioquia y el Valle del Cauca. En otras palabras: si hubo dineros malditos en sus arcas, sólo que no contaban con el respaldo de un Cartel (tal como aconteció con América de Cali y Nacional de Medellín) sino con la presencia peregrina de algunos narcotraficantes entusiastas que introdujeron parte de sus ilícitas ganancias en el negocio del fútbol.

La historia negra de Millonarios comienza con Edmer Tamayo, ya muerto, de quien se afirma era propietario de un cargamento de 2000 kilos de cocaína, capturado en septiembre de 1982. A Tamayo también se le vincula como propietario de un cargamento de 65 kilogramos de cocaína incautado en Barranquilla. Los intereses de Tamayo fueron representados por los abogados Germán y Guillermo Gómez, vinculados por la justicia colombiana con el capo del cartel de Cali, Gilberto Rodríguez Orejuela. Más adelante, en una rápida y oscura transacción, un socio de Escobar llamado Gonzalo Rodríguez Gacha, alias "El Mejicano", se convirtió en el nuevo mayor accionista del elenco albiazul. Pesquisas posteriores de las autoridades judiciales y de policía revelaron que, entre 1987 y 1988, Rodríguez Gacha apoyó con el corazón y la chequera al equipo, que vivió un nuevo juego dorado ${ }^{60}$. De esos dos años son las sospechadas coronas albiazules que en su tiempo fueron denunciadas a los cua-

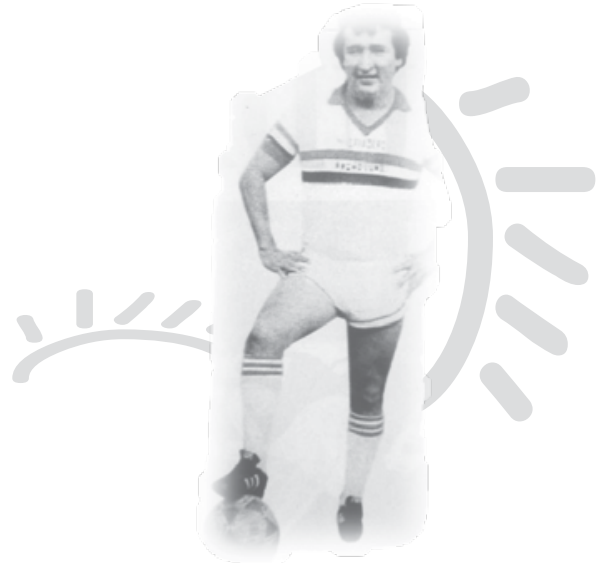

tro vientos por el actual director técnico de la Selección Colombia, Jorge Luis Pinto, quien señaló públicamente a Luis Augusto García (ex entrenador de la selección absoluta) "como sobornador de jugadores y árbitros para obtener buenos resultados con Millonarios"61.

Según el investigador José Cipriano Ramos ${ }^{62}$, "El Mejicano" premiaba con un millón de pesos a todo el que anotara un gol en los partidos del torneo profesional, por lo que los jugadores de Millonarios se esforzaban al máximo para romper las redes adversarias. Después de los grandes triunfos, invitaba al equipo a su finca de $\mathrm{Pa}$ cho (Cundinamarca), cerca de la capital, para premiar a los goleadores y celebrar con whisky y carnes de cerdos sacrificados a balazos. Los futbolistas agradecidos no decían "muchas gracias" sino "muchas gachas"63. Vale decir que "El Mejicano" fue abatido en una espectacular operación de

\footnotetext{
60 Ramos, op. cit., p. 143.

61 Hernán Pelaez Restrepo. El milagro del fútbol colombiano. Bogotá: Editorial Oveja Negra, 1994, p. 176.

62 Ramos, op. cit., p. 144.

63 Juego de palabras en el que la expresión "gracias" es sustituida por la del apellido del narcotraficante Gacha.
} 
la policía en diciembre de 1989, pero su familia -a través de su esposa- siguió al frente del equipo hasta que fue objeto de extinción de dominio por parte de la Dirección Nacional de Estupefacientes que hoy administra el 29,7\% de las acciones de MiIlonarios incluida su cotizada sede deportiva ubicada al norte de Bogotá y que está avaluada en 2500 millones de pesos. Ante esa situación y recurriendo a la ironía, no sería incorrecto afirmar que en el mundo del fútbol criollo, el equipo capitalino es, después de la Selección Nacional, patrimonio del Estado colombiano.

Pero si por el lado de las toldas azules llueve, por las rojas no escampa: el Independiente Santa Fe, el equipo de los ro${ }^{10 S^{64}}$ auténticos ${ }^{65}$, también tiene su oscuro pasado; el equipo fue controlado primero por el llamado Grupo Inverca, de Fernando Carrillo, quien fue señalado como propietario de una cadena de droguerías en Colombia, a través de la cual distribuía insumos para el refinamiento de coca. En noviembre de 1978 informes policiales afirmaban que Carrillo tenía a Miami como centro de distribución del alcaloide que producía y por ello no causó extrañeza que en mayo de 1981 se le hicieron cargos por haber participado en envíos de cocaína a La Florida. Después de esas graves acusaciones Carrillo despareció del club sin dejar rastros ${ }^{66}$. Luego el equipo santafereño pasó a manos de Silvio y Fanor Arizabaleta Arzayus, narcotraficantes vallecaucanos que legaron su dominio del club albirrojo al colega de negocio Justo Pastor Perafán, hoy condenado en Estados Unidos, que antes de ser atrapado por la DEA entregó la dirección ejecutiva del equipo a César Villegas quien pagaría los platos rotos de su testaferrato, con un publicitado carcelazo en el que la justicia colombiana aplicó "una pena ejemplar en vista del nivel de estudios del doctor Villegas y de su condición de dirigente deportivo"67. Así Villegas se adelantaría unos años al también presidente santafereño, Luis Eduardo Méndez, relacionado al principio de este artículo como un convicto de la ley norteamericana.

La addenda de los dos clubes bogotanos es tan triste como la historia del último tiempo: hoy Millos y Santa Fe están intervenidos por el Instituto Colombiano del Deporte (Coldeportes) por razón de sus debilidades institucionales detectadas por la Superintendencia de Sociedades ${ }^{68}$; igualmente, las dos escuadras futboleras están cerca de la ruina económica por lo que tuvieron que acogerse a la Ley 550 o "Ley de quiebras" y si no marchan deportivamente es por razones atribuibles, entre

\footnotetext{
64 Rolo es el gentilicio popular de bogotano.

65 Periodistas bogotanos de vieja guardia como Daniel Samper Pizano, Yamid Amat, Guillermo 'La Chiva' Cortés y Julio Sánchez Cristo; además del vicepresidente Francisco Santos y buena parte de los rolos de más de cincuenta años son hinchas del sufrido Santa Fe.

66 Castillo, op. cit., p. 98.

67 Gabriel Briceño. "La increíble historia de los dirigentes y sus chequeras desalmadas, II Parte" Deporte Gráfico No. 1082 (Diciembre), 1998, p. 39.

68 Organismo encargado de vigilar y regular el sector en donde se encuentran los clubes y las corporaciones deportivas en Colombia que señaló, desde mediados de los 80 's, la presencia de dineros calientes en los equipos de fútbol.
} 
otras causas, al desgreño administrativo fomentado por la prioridad de lavar activos y satisfacer ambiciones personales antes que incurrir en eficiencia gerencial y en eficacia competitiva.

Concluimos el relato de los negociados narcotraficantes en plena área de 16 con 50 , diciendo que otros equipos de provincia como el Deportes Tolima, el Deportivo Pereira, el Unión Magdalena, el Atlético Bucaramanga, el Deportes Quindío, entre otros clubes de la primera, la segunda e incluso la tercera división, han enlodado su historia y sus títulos con las turbias relaciones con "hombres del maletín" que han aportado a sus arcas dinero perverso a cambio de prestigio social o coartadas financieras para sus fraudes, trampas e ilícitos.

\section{Pitazo final, pero el partido aun no acaba}

No parece haber dudas de que el narcotráfico posó sus nefastas garras en la nación colombiana dejando muy pocos claros para escabullirse de su hediondez; tampoco nadie hoy día es tan ingenuo de pensar que nuestro fútbol permaneció incólume frente a las tulas atestadas de dólares que se pasearon por los campos de entrenamiento, los camerinos, los salones de reunión de directivos y las mismísimas salas de redacción de los medios de comunicación. La droga y su estela maldita se enseñorearon de nuestro país y lograron algo que parecía imposible: subordinaron a la orgullosa clase política que -hasta entonces- sustentaba su poder en

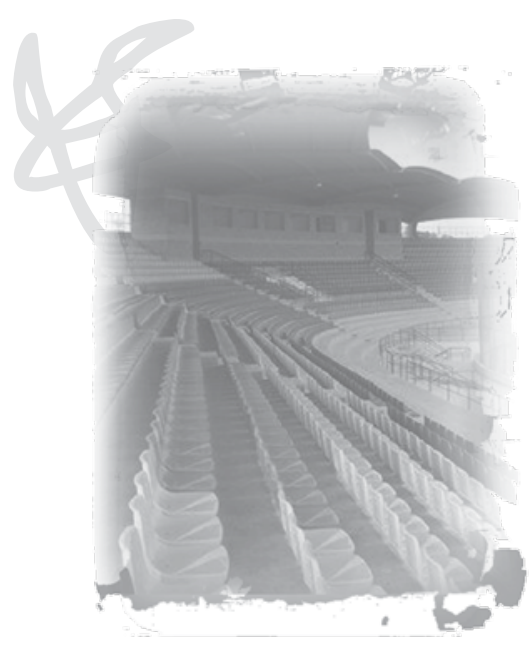

la falacia de la opulencia y pusieron de rodillas al establecimiento; cuestión que no habría inquietado a nuestros vecinos (especialmente al del norte del río Bravo) de no ser porque centenas de contenedores (de la más diversa forma) desembarcan en sus predios, inundando de hedonismo a la insaciable juventud que troca billetes de a dólar por miligramos de placer sintético. Claro, el problema es que ese negocio -en la perspectiva de EE.UU.- no paga impuestos y que sus generosas ganancias no se quedan en suelo estadounidense iHe ahí un problema de elemental comprensión económica!

Pero más allá de seguir esgrimiendo argumentos en contra del narcotráfico (que no se acabará mientras haya la descomunal demanda); más allá de exigir la inmediata despenalización de la libre circulación de las drogas (lo que derrumbaría el imperio de las mafias alrededor suyo) y trascendiendo la queja lastimera que tanto nos ha caracterizado (los últimos cinco presidentes colombianos solo supieron pedir, con ojos aguados, helicópteros y dólares para mitigar el peso de nuestros muertos por violencia narcotraficante), conviene que todos reflexionemos sobre 
lo que ha significado el fenómeno narco en Colombia y cómo transformó nuestra sociedad (e incluso nuestra cultura). Pues bien, ese ejercicio analítico es tarea ardua y de largo aliento, por lo que resumo el deber citando una metáfora que lo denota: "la cultura del atajo", detectada por el sociólogo Álvaro Camacho Guizado, que se valió de la mirada profunda del etnógrafo para descubrirla y acudió a la creatividad del ladino para acuñarla bajo esa expresión verbal.

La cultura "del camino más fácil" se sintetiza de forma óptima en el argot popular que la llama "el traquetismo" o "la cultura del traqueto" ¿Quién es el traqueto? La verdad no es difícil describirlo cuando se ha vivido en Colombia y, más aun, cuando se han conocido ampulosos ambientes como el del fútbol profesional colombiano. Un traqueto es un jugador que recibe un soborno para perder o un profesor que acepta un ingreso extra para promover un estudiante que no lo merece o una mujer 'prepago'69 que vende su cuerpo para comprarse un mejor modelo de teléfono celular. Pero traqueto es también quien ofrece el estímulo; traqueto es el que supedita su felicidad al valor del dinero y lo que se puede conseguir con él. Traqueto es el que aprecia su poder en ceros a la derecha; traqueto es el que vive en el reino de la suposición, la engañifa, la falacia y la apariencia. Traqueto es el que vive "drogado" de la realidad: traqueto es el narcotraficante directo y el que disfruta su entorno.

¿Será la sociedad colombiana, una sociedad traqueta? Si y No. Si, cuando se observa que los grupos alzados en armas (de extrema derecha como los paramilitares e izquierda como las guerrillas marxistas y guevaristas) subsidian buena parte de sus acciones con los generosos réditos de la droga y la extorsión: están obrando con la ley del menor esfuerzo expresado en la explotación del placer y el dolor ajeno. De contera, pese a lo atroz del conflicto, del presidente para abajo todos niegan la guerra civil y luego aparecen en encuestas mundiales como el segundo país más feliz del mundo ${ }^{70}$ ¿No es eso simulación? ¿No es eso un remedo del escapismo artificioso del esnobista? ¿O será que eso es simple olvido? Entonces ¿Será el olvido una estrategia terapéutica ante tanto dolor?... Probablemente, pero volvamos a lo nuestro: No se es traqueto cuando se asume la mano como llega; cuando se acepta que nuestra patria tiene cerca de dos millones de desplazados y cerca de cuarenta mil refugiados. No se es traqueto cuando se reconoce que políticos y paramilitares edificaron su imperio con el terror ciudadano; No se es traqueto cuando se admite que la dirigencia nacional de los últimos treinta años se ha alimentado con las ilegitimas ganancias del narcotráfico.

\footnotetext{
69 Expresión coloquial para designar a las mujeres que intercambian sexo por bienes en especie; sean estos elementos tecnológicos, ropa de finas marcas o una vida de elegancia y glamour.

70 Alusión a una encuesta, de reciente aparición en la prensa, en la que Colombia, pese a todos los pronósticos, aparece en el segundo lugar del escalafón mundial de felicidad, apenas derrotada por una pequeña isla del Pacífico oriental.
} 
Aceptar la cruda realidad, sin eufemismos ni disimulos (y sin amnesia provocada $)^{71}$ es la mejor forma de negar el traquetismo. Claro que todavía restará la fase más importante; la de la acción de cambio, de mejora, de transformación, de movilización... ¿Y el fútbol? Ah... iel fútbol! El fútbol siempre ha sido una ilusión, una ensoñación, un sub- mundo. El fútbol, sobre todo el de Colombia (pero no se descarta que pase en todas partes), contiene rasgos sui generis que lo hacen único en su capacidad para mitificar, por lo que sus efectos, "narcóticos" si se prefiere, afectan a la sociedad tanto como pueda resistirlo, que es lo mismo que afirmar que afecta a la sociedad tanto como dure el comienzo del siguiente partido o como tarde el arranque del siguiente campeonato: el fútbol es el reino de la esperanza posible (siempre se puede ganarle al mejor equipo; así sea "un día de estos") por lo que hacerle un juicio al fútbol es tan inoficioso como castrar un alacrán.

Claro que si se persiste en la idea de hacerle un juicio político al fútbol, amparado en la máxima esgrimida por los sindicatos europeos de la década del setenta y reproducida por los intelectuales de izquierda de América Latina, que -parafraseando a Marx- reza "el fútbol es el opio del pueblo"72; tendríamos que mencionar tres episodios de poderoso simbolismo en la historia colombiana: el primero es la abrupta creación del torneo profesional de fútbol colombiano que fue estrenado a las volandas en 1948, dos meses después del asesinato del líder popular Jorge Eliécer Gaitán cuya muerte recrudeció la lucha bipartidista en Colombia conocida como "La Violencia"73. El segundo y tercer hecho van de la mano: son las órdenes perentorias de los gobiernos de turno y de los directivos de medios de comunicación para transmitir en los canales de televisión pública partidos de fútbol y la sospechosa difusión noticiosa de los mismos en la radio y la prensa, que disimularon y ocultaron dos tragedias nacionales: la toma del Palacio de Justicia por parte de la guerrilla del M-19 (en 1985) y la muerte de Luis Carlos Galán (en agosto de 1989) ${ }^{74}$; ello como evidente estrategia para exorcizar la protesta popular ante sendos magnicidios.

71 Resulta muy ilustrativo que por estos días, en el marco de la controvertida Ley de Justicia y Paz que cobija a los paramilitares que se entregaron a la justicia, se asista a la feria del olvido y la macabra distorsión de los hechos: se pasa de largo muchas masacres y varias de ellas son presentadas como "hechos de guerra". El colmo del cinismo es el de los paramilitares desmovilizados que han acudido a la figura de la amnesia para eludir la delación de sus vejámenes.

72 Rubén Olive y Arlei Damo. Fútbol y cultura. Bogotá: Norma, 2001. La sentencia original, escrita por Karl Marx en su Contribución a la crítica de la filosofía del derecho de Hegel (1844), dice "La religión es el opio de los pueblos".

73 El 'Negro' Gaitán, candidato presidencial por el partido liberal, fue asesinado el 9 de abril de 1948 en un hecho rotulado por la historia como "El Bogotazo"; magnicidio político que agudizó el conflicto civil entre los dos partidos hegemónicos de Colombia: el conservador y el liberal.

74 El presidente Belisario Betancur y su ministra de comunicaciones Noemí Sanín, ordenaron que se televisara el juego entre Millonarios y el Unión Magdalena la noche del 6 de noviembre de 1985; así mismo, es reveladora la intensidad con la que la programadora Caracol Televisión promocionó el partido de eliminatoria mundialista entre Colombia y Ecuador en detrimento del cubrimiento noticioso al funeral del asesinado Luis Carlos Galán Sarmiento. 
¿Qué se puede pensar de una patria que refunde su tragedia política en la impostada fiesta del gol? Responder tamaño interrogante es atrevido y aventurado; no obstante se puede acudir a la lúcida labia de Francisco Maturana quien en uno de los raptos filosóficos que lo han hecho célebre, sentenció: "se juega como se es"; en esa perspectiva sociológica habría que concluir que nuestra nación es más ilusoria de lo que parece ya que reposa su proyecto de unidad en una ilusión mayor; ya que descansa su idea de nación en prácticas alteradas y desnaturalizadas como la del fútbol y la política alimentados con gasolina narcotraficante ${ }^{75}$ ¿Será que es cierta aquella máxima garciamarquiana que dice que en Colombia la realidad supera la ficción? ¿Será que el "realismo mágico" de Macondo se extiende a todos los ámbitos de la geografía nacional?...
¿Será que ese argumento es otra excusa escapista, amnésica y traqueta?

Finalizamos recordando que Roberto Da Matta y Eduardo Archetti dibujaron al Brasil y a la Argentina a partir del estilo de juego de sus selecciones de fútbol; la nación de la samba se puede resumir en las cualidades de Pelé y la de los gauchos en las picardías de Maradona ${ }^{76}$; así mismo, Colombia se hará a conocer en todo el orbe ya no por el gángster y el Nóbel ${ }^{77}$, sino por el tensionadito bacano del 'loco' René Higuita que con esa frase resumía su ansiedad de lucha ante la divertida adversidad del medio. Esa es la mejor radiografía del colombiano: la del ser que se permite ilusionarse sabiendo que tiene pocas posibilidades de éxito y que desconoce si realmente le interesa ganar; la del sujeto para el que -como también dijera Maturana- perder es ganar un poco.

\footnotetext{
75 En este segundo semestre de 2007 se incrementó la presión de la prensa nacional e internacional en torno a los supuestos vínculos del presidente Álvaro Uribe Vélez con el narcotráfico. Además de los citados libros de Fabio Castillo y de Virginia Vallejo que aseguran tener pruebas de presuntos encuentros del primer mandatario de los colombianos y de algunos de sus familiares y allegados con la mafia (de hecho el ideólogo del gobierno Uribe, José Obdulio Gaviria, es primo de Pablo Escobar), está el hecho de las numerosas acusaciones periodísticas que pretenden relacionarlo con los paramilitares; situación que nos recuerda el Proceso 8.000 que conmocionó la historia reciente de Colombia.

76 Roberto Da Matta (comp). O universo do futebol: esporte e sociedade brasileira. Río de Janeiro: Pinakotheke, 1982. Eduardo Archetti. Masculinidades. Fútbol, tango y polo en la Argentina. Buenos Aires: Antropofagia, 2003.

77 Walter Broderick. Camilo: el cura guerrillero. Bogotá: Intermedio Editores, 2005, p. 7.
} 